\title{
Light-Weight Perlite Medium Cultivation of Plants used in Extensive Green Roof Feasibility Studies
}

\author{
Chiou-Chuan Chen ${ }^{1,}$, Yi-Hong Peng ${ }^{2}$, b* \\ ${ }^{1}$ Assistant Professor, Chung Chou University of Science and Technology, Department of \\ Landscape Architecture, No. 6, Lane 2, Sec. 3, Shanjiao Rd., Yuanlin Township, Changhua County, \\ Taiwan (R.O.C.). \\ ${ }^{2}$ Master Degree, Cheng Kung University, Department of Architecture, \\ No. 1, University Rd, Tainan, Taiwan (R.O.C.). \\ aland530308@yahoo.com. tw, peter541223@yahoo.com.tw
}

Keywords: Extensive Green Roof, Medium, Perlite, Plants, Sandy Loam

\begin{abstract}
We tested 8 plants and 3 medium and tested perlite base, thus achieving the results. The green coverage for media S6 (perlite to sandy loam is 8:2) is suitable for Alpinia speciosa the best growth $1040.5 \mathrm{~cm}^{2}$, followed is Duranta repens the growth $675 \mathrm{~cm}^{2}$, with Portulaca grandiflora as the third growth $365.12 \mathrm{~cm}^{2}$. The green coverage for media S7 (perlite to sandy loam is 5:5) is suitable for Alpinia speciosa the best growth $843.93 \mathrm{~cm}^{2}$, followed is Duranta repens the growth $587.38 \mathrm{~cm}^{2}$, with Zoysia matrella as the third growth $435.81 \mathrm{~cm}^{2}$. The green coverage for media S8 (perlite to sandy loam is 2:8) is suitable for Alpinia speciosa the best growth $501.03 \mathrm{~cm}^{2}$, followed is Duranta repens the growth $324.39 \mathrm{~cm}^{2}$, with Zoysia matrella as the third growth $298.55 \mathrm{~cm}^{2}$. Perlite to sandy loam medium is more suitable for Duranta repens, Alpinia speciosa, and Zoysia matrella with growth. S6 medium the best green coverage growth (biomass) $3185.49 \mathrm{~cm}^{2}$. Eight kinds of plants Alpinia speciosa the best green coverage growth (biomass) $2385.46 \mathrm{~cm}^{2}$. Different media prescriptions are well-grown planting combinations, in which one can choose different plant species based on the environment and in order to create biodiversity. This can be achieved to reduce the building load and may provide a good environment for the growth of plants and create space in favor of green roofs.
\end{abstract}

\section{Introduction}

Urban land cover artificial sites, green space decreasing, causing urban heat island effect (7), increase the rate of urban green cover to mitigate environmental pressures, scholars advocate green roofs to increase the green covering reached to reduce surface runoff, urban floods delayed, ease to improve the urban heat island effect, using green materials as a matrix of planting, maintaining plant growth, reaching environmental protection, light, waste reduction, as a green roof material purposes of this study $(2,3,4)$.

In view of global warming, urban heat island effect, urban ecological corridor, storm water, reduced runoff, and other issues, during the process of land development and construction it has been helpful to start thinking about how a piece of natural land can improve the global environment $(1,2,3,4,5,7,9,11)$.

Basic needs that planting green roof growing media, the traditional construction method mostly general soil (loam or sandy loam), but consider reducing the load floor, should be applied as a lightweight media, to build the body of the load was lighter, and more with safety $(2,3,4)$.

After the site is actually observed as well as public works budgeted found that the industry practice the construction of green roofs completed waterproofing and pavement works on the roof after the laying of the drainage board and non-woven, the choice of growing media are mostly direct backfill sandy loam, this experimental studies of hope can be, the choice of current market easily accessible and lighter cultivation medium, instead of using one 100 percent of the sandy loam, 
with a view to achieve lower structural loads buildings and provide an ideal environment for the growth plant $(1,2,3,4)$.

\section{Materials and Methods}

Empirical Location. Taiwan (Tainan), Cheng Kung University Department of Architecture roof.

Empirical Facilities. In this study the choice of plant pots, growing media thickness should be $10 \mathrm{~cm} \sim 15 \mathrm{~cm}(4,8)$, to facilitate the turf and shrub in irrigation water on the growth supplemented where planting is possible. For planting and growth, the average growth of the crown is in a circular manner (Figs. 1, 2).

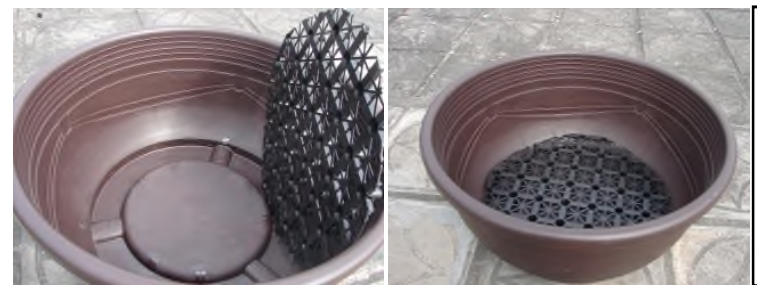

Fig. 1 Plant pot containers.

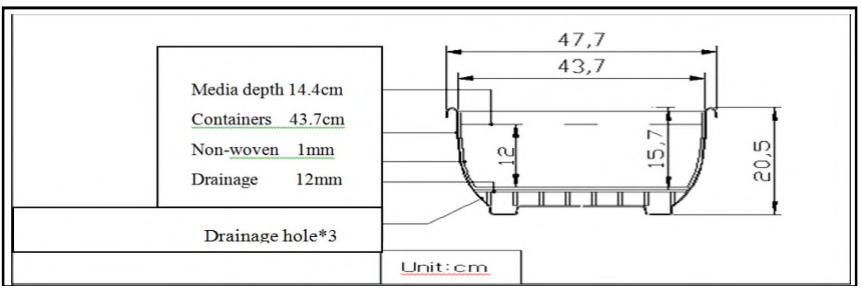

Fig. 2 Plant pot containers' cross-section.

Medium. Media mixing ratio of deliberate industry and research experience selected.

Table 1. Prescriptions of medium.

\begin{tabular}{|l|c|c|c|}
\hline No. & S6 & S7 & S8 \\
\hline Media & Perlite 20\%, Sandy loam $80 \%$ & Perlite 50\%, Sandy loam 50\% & Perlite 80\%, Sandy loam 20\% \\
\hline
\end{tabular}

Table 2. Amount of sample media.

\begin{tabular}{|c|c|c|c|}
\hline Medium & Medium volume & Medium weight & Total Medium weight \\
\hline \multirow{2}{*}{$\begin{array}{l}\text { Perlite } 20 \% \\
\text { Sandy loam } 80 \%\end{array}$} & $0.0031 \mathrm{~m}^{3}$ & $0.31 \mathrm{~kg}$ & \multirow{2}{*}{$17.174 \mathrm{~kg}$} \\
\hline & $0.0124 \mathrm{~m}^{3}$ & $16.864 \mathrm{~kg}$ & \\
\hline \multirow{2}{*}{$\begin{array}{l}\text { Perlite } 50 \% \\
\text { Sandy loam } 50 \%\end{array}$} & $0.00775 \mathrm{~m}^{3}$ & $0.775 \mathrm{~kg}$ & \multirow{2}{*}{$11.315 \mathrm{~kg}$} \\
\hline & $0.00775 \mathrm{~m}^{3}$ & $10.54 \mathrm{~kg}$ & \\
\hline \multirow{2}{*}{$\begin{array}{l}\text { Perlite } 80 \% \\
\text { Sandy loam } 20 \%\end{array}$} & $0.0124 \mathrm{~m}^{3}$ & $1.24 \mathrm{~kg}$ & \multirow{2}{*}{$5.456 \mathrm{~kg}$} \\
\hline & $0.0031 \mathrm{~m}^{3}$ & $4.216 \mathrm{~kg}$ & \\
\hline
\end{tabular}

Planting Sample. The study selected 8 plant species: Duranta repens, Alpinia speciosa, Murraya paniculata, Portulaca grandiflora, Zoysia matrella, Liriope platyphylla, Podocarpus costalis, and Spathoglottis plicata), each with 9 seedlings, for a total of 72 seedlings. The study was equipped with 3 kinds of plant pots in different media containers $(4,8)$ with plant cultivation and a detailed view of each seedling planted, after cutting bad branches and leggy branches $(5,6,7,10,14)$.

Experiment and Record. This study had 24 sample group (3 Repeat), covering 3 kinds of planting medium and 8 planting kinds, for a total of 72 groups. The experimental construction date was February 13, $2011(2,3,4,5)$.

$\mathrm{pH}$ value measurement method. The electrode method to detect the $\mathrm{pH}$ of each sample, $\mathrm{pH}$ testing equipment for the SUNTEX PH METER TS-110.

\section{Photo Data Record.}

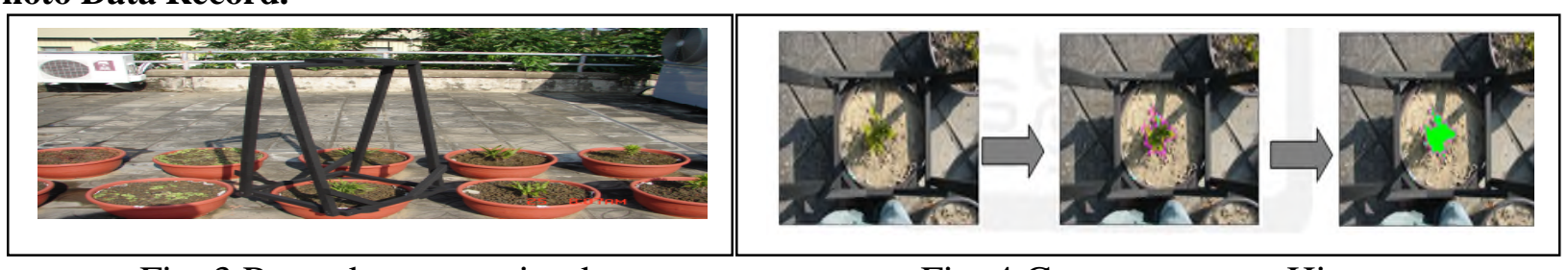

Fig. 3 Record camera tripod.

Fig. 4 Green coverage History. 
Sampling Frequency and Number. From the date of the beginning of the experiment, for the preceding month the photograph mode recorded the green coverage (Fig. 3, 4) $(4,6,9,11)$. This study conducted the process on July 24, 2011, 160 days later, with a month as an observation period. The camera recorded 5 times and the planting measuring 5 times.

Statistical Methods. For the planting medium pH value, Excel 2013 recorded pH changes made after the graph to understand the trends. The green coverage data was entered into the Excel 2013 file content, in order to analyse the same planting in a different media green coverage of change, so as to find out the ideal cultivated plant cultivation medium $(2,3,4,5,7,8)$.

\section{Results and Discussion}

This study focused on lightweight media suitable for landscape plants. For facilities with green roofs, this study added the original medium sandy loam in different proportions of lightweight media, perlite, and sandy loam to examine different proportions after the planting medium (Table 1, 2) was used in the plant along with the growth of high-performance green coverage in different media. The appearance of the physiological condition of the plant can determine the suitability of the planting medium. The ratio of the various media, depending on the experimental results, can help verify the proper proportion of the medium.

Medium pH Value Detection. The $\mathrm{pH}$ of the medium is detected for different media at the beginning, mid-term, and end of the sampling, thus providing the sample testing results (Table 3, Fig. 5).

Table 3. Medium pH value detection history.

\begin{tabular}{|r|r|c|c|c|}
\hline & $\begin{array}{r}\text { Sampling period } \\
\text { Date }\end{array}$ & Beginning & Mid-term & End \\
\cline { 3 - 5 } & days & $2011 / 2 / 13$ & $2011 / 4 / 30$ & $2011 / 7 / 27$ \\
\cline { 3 - 5 } & & 1 & 77 & 165 \\
\hline Medium & Ave. value 1 & Ave. value 2 & Ave. value 3 \\
\hline S6 & Perlite 20\% + Sandy loam 80\% & 7.44 & 7.86 & 7.61 \\
\hline S7 & Perlite 50\% + Sandy loam 50\% & 7.54 & 8.01 & 7.61 \\
\hline S8 & Perlite 80\% + Sandy loam 20\% & 7.65 & 7.94 & 7.74 \\
\hline
\end{tabular}

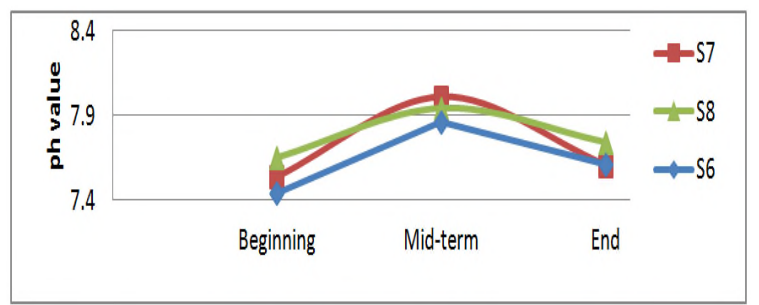

Fig. 5 Perlite Medium $\mathrm{pH}$ value detection graph.

Medium $\mathrm{pH}$ value is detected, most of the medium showed a low-alkaline environment. (Table 3, Fig. 5).

Growth Planting History. We tested 8 plants and 3 medium and tested perlite base, thus achieving the results.

S6 (Perlite to Sandy loam is 2:8) eight kinds of plant growth analysis.

The green coverage for media S6 (perlite to sandy loam is 2:8) is suitable for Alpinia speciose. The best growth $1040.5 \mathrm{~cm}^{2}$, followed is Duranta repens the growth $675 \mathrm{~cm}^{2}$, with Portulaca grandiflora as the third growth $365.12 \mathrm{~cm}^{2}$ (Fig. 6). 


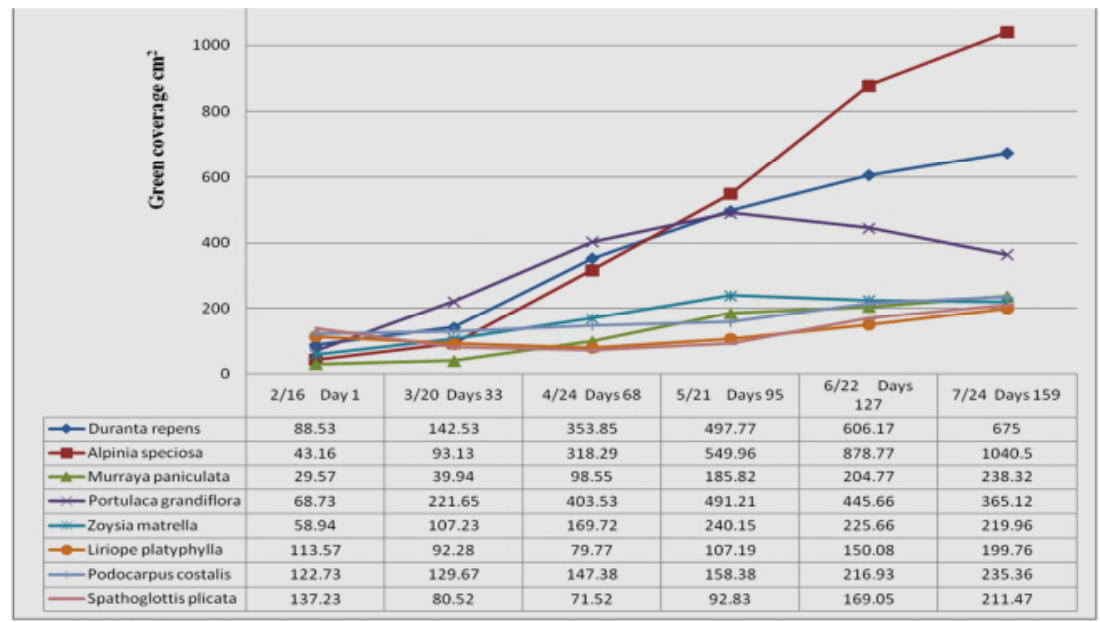

Fig. 6 S6 (Perlite to Sandy loam is 2:8) eight kinds of plant growth biomass graph.

S7 (Perlite to Sandy loam is 5:5) eight kinds of plant growth analysis.

The green coverage for media S7 (perlite to sandy loam is 5:5) is suitable for Alpinia speciosa the best growth $843.93 \mathrm{~cm}^{2}$, followed is Duranta repens the growth $587.38 \mathrm{~cm}^{2}$, with Zoysia matrella as the third growth $435.81 \mathrm{~cm}^{2}$ (Fig. 7).

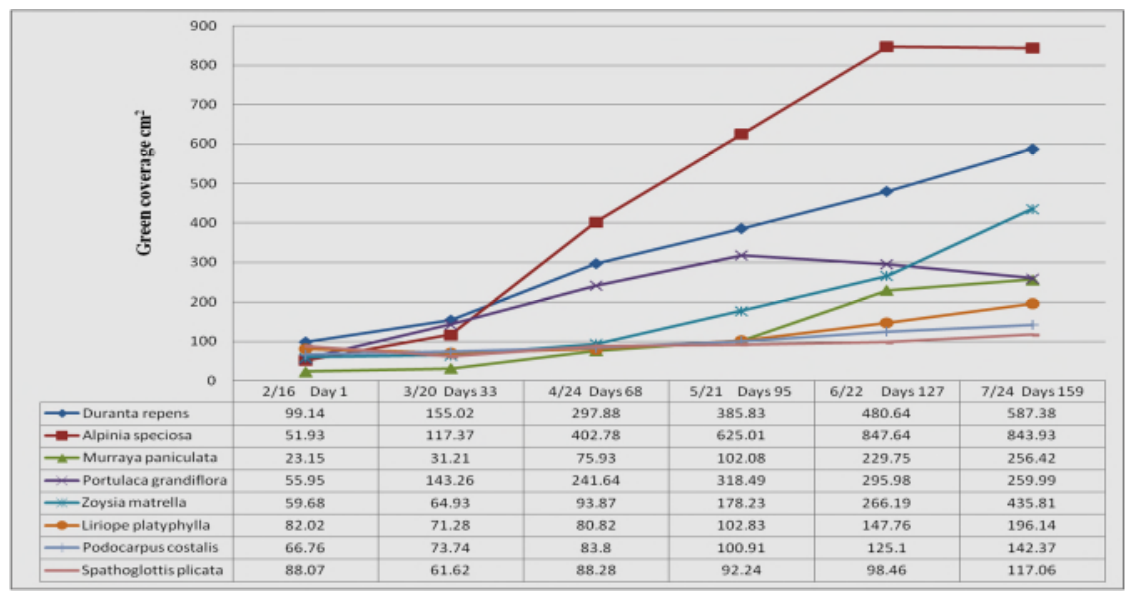

Fig. 7 S7 (Perlite to Sandy loam is 5:5) eight kinds of plant growth biomass graph.

S8 (Perlite to Sandy loam is 8:2) eight kinds of plant growth analysis.

The green coverage for media S8 (perlite to sandy loam is 8:2) is suitable for Alpinia speciosa the best growth $501.03 \mathrm{~cm}^{2}$, followed is Duranta repens the growth $324.39 \mathrm{~cm}^{2}$, with Zoysia matrella as the third growth $298.55 \mathrm{~cm}^{2}$ (Fig. 8).

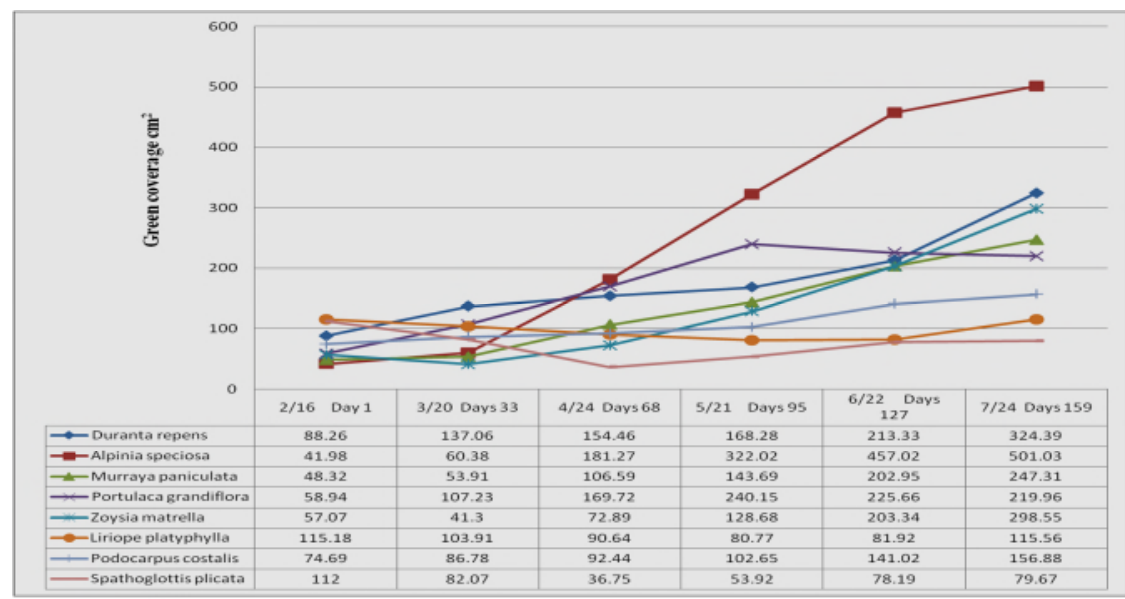

Fig. 8 S8 (Perlite to Sandy loam is 8:2) eight kinds of plant growth biomass graph. 
Perlite to sandy loam medium is more suitable for Duranta repens, Alpinia speciosa, and Zoysia matrella with growth. S6 medium the best green coverage growth (biomass) $3185.49 \mathrm{~cm}^{2}$. Eight kinds of plants Alpinia speciosa the best green coverage growth (biomass) $2385.46 \mathrm{~cm}^{2}$.

Duranta repens. From the green coverage observed and recorded and the green coverage of the graph (Fig. 9), the growth of Duranta repens S6 (Perlite 20\% + Sandy loam $80 \%$ ) green coverage $\left(675 \mathrm{~cm}^{2}\right)$ in the media is significantly superior versus the other media. The study observed a medium to high growth curve for Duranta repens S7(Perlite 50\% + Sandy loam 50\%). Here, the more than S8 (Perlite 80\% + Sandy loam 20\%) medium and S8 medium Duranta repens height growths are the worst. Thus, S6 is more suitable for Duranta repens growth.

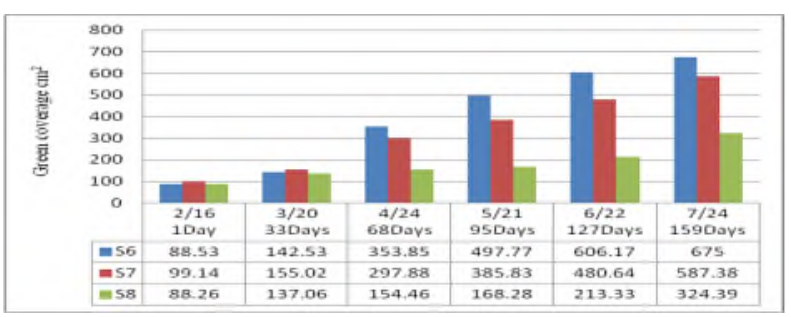

Fig. 9 Duranta repens green coverage graph.

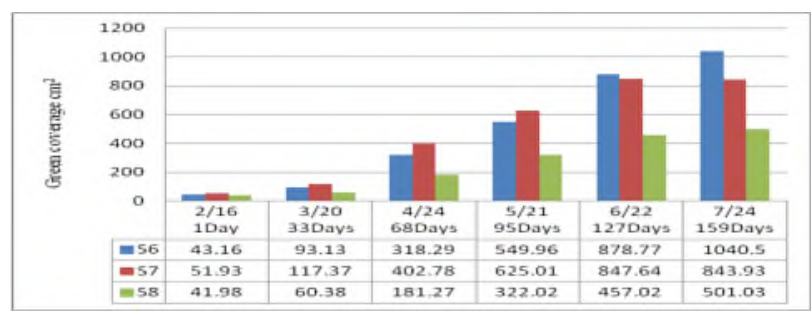

Fig. 10 Alpinia speciosa green coverage graph.

Alpinia Speciosa. The S6 medium is more suitable for Alpinia speciosa (Fig. 10), where the optimum growth temperature is $20 \sim 30^{\circ} \mathrm{C}$. By observation, the high growth curve shows a proportional relationship between green coverage, with S6 of the green covering $\left(549.96 \mathrm{~cm}^{2}\right)$ from May. The trend is gradually increasing, where the S7, S8 medium during the planting of the first 127 days slightly slows down away from the green coverage curve. Collocation Alpinia speciosa likes weather that is hot and humid, whereas the general growth of irrigation for Alpinia speciosa still seems inadequate.

Murraya Paniculata. In S7 the performance of the media better than the other two media (S6, S8). By the green coverage of the graph (Fig. 11), S6 medium in the sample since sixty-eighth days the green cover $\left(98.55 \mathrm{~cm}^{2}\right)$ increased health trend, $\mathrm{S} 7$ medium in the sample since ninety-fifth days the green cover $\left(102.08 \mathrm{~cm}^{2}\right)$ increased health trend, that increase the amount of green coverage in S7 the best performance, followed by S6 and S8, S6 and S7 period of increasing the amount of green cover, which may be related to changes in $\mathrm{pH}$ value, it can be seen.
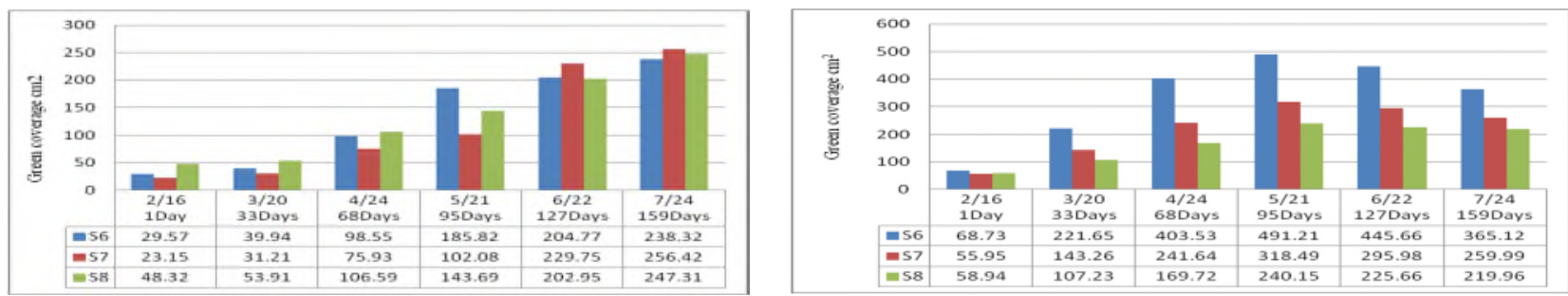

Fig. 11 Murraya paniculata green coverage graph. Fig. 12 Portulaca grandiflora green coverage graph.

Portulaca Grandiflora. Portulaca grandiflora is drought-tolerant succulents. , ninety-fifth days increase green coverage of the fastest medium $\mathrm{S} 6\left(491.21 \mathrm{~cm}^{2}\right), \mathrm{S} 7\left(318.49 \mathrm{~cm}^{2}\right)$ second, $\mathrm{S} 8(240.15$ $\mathrm{cm}^{2}$ ) slowest (Fig. 12), the fourth observation after the measurement, due in May, June, July in rainy climate, green coverage of the three curves are showing a downward trend, the decline was minimal S8, S6 is the significant, so the Perlite media group for planting Portulaca grandiflora needles when weather conditions and watering should be classified as necessary considerations.

Zoysia Matrell. The growth trend's turf coverage is expressed in Fig. 13. The S7 medium Zoysia matrell green coverage $\left(435.81 \mathrm{~cm}^{2}\right)$ is the maximum, followed by S7 followed, with $\mathrm{S} 8\left(298.55 \mathrm{~cm}^{2}\right)$ as the worst. S6, S7 beginning (February to May) green cover rate falling instead of rising (Fig. 10). 


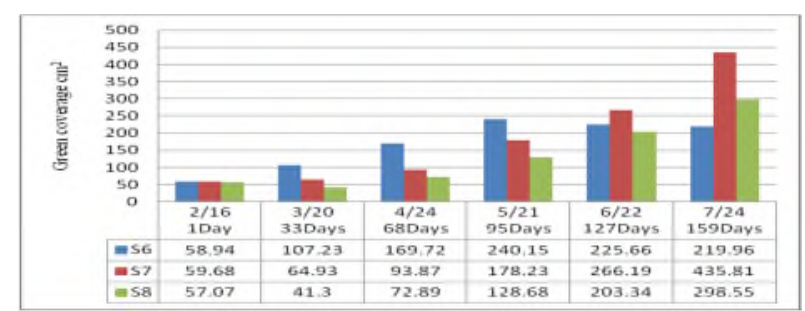

Fig. 13 Zoysia matrell green coverage graph.

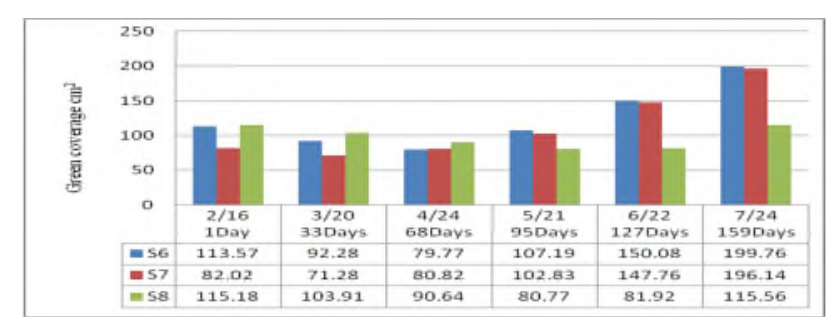

Fig. 14 Liriope platyphylla green coverage graph.

Liriope Platyphylla. Green coverage graph greater change of Liriope platyphylla three samples of beginning green covering is decline (Fig. 14). S8 sample beginning green coverage lower than S6 and S7 significantly. S6, S7 green coverage of since sixty-eighth days green cover increased health trend. The increase in green coverage for Liriope platyphylla is from the best medium of S6(199.76 $\left.\mathrm{cm}^{2}\right)$, followed by S6 followed, with $\mathrm{S} 8\left(115.56 \mathrm{~cm}^{2}\right)$ as the worst.

Podocarpus Costalis. For S6, S8 in the beginning and mid-term growth trends of green coverage gentle, there is only a more obvious increase during the period of 95 to 127 days(May and June) (Fig. 15). The increased green coverages of Podocarpus costalis for S6 and S8 are greater than S7; the best medium is $S 6\left(235.36 \mathrm{~cm}^{2}\right)$, followed by $S 8$, with $\mathrm{S} 7\left(142.37 \mathrm{~cm}^{2}\right)$ as the worst.
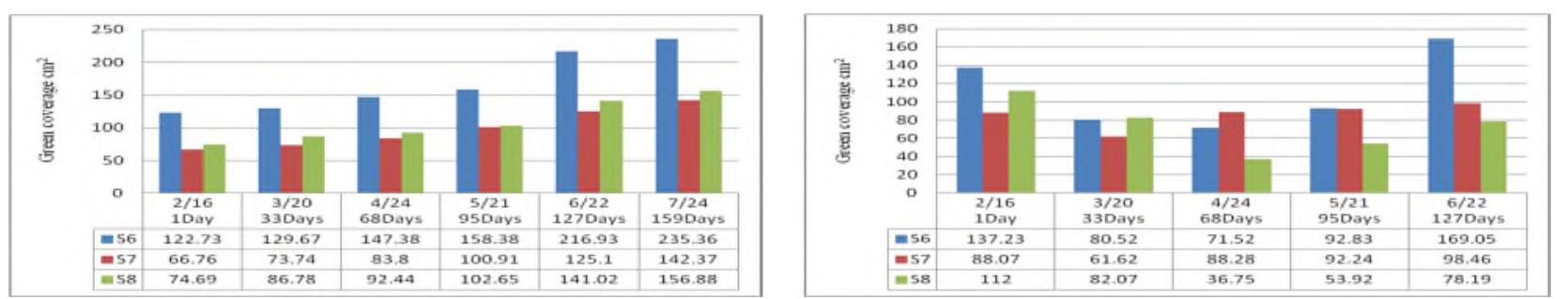

Fig. 15 Podocarpus costalis green coverage graph. Fig. 16 Spathoglottis plicata green coverage graph.

Spathoglottis Plicata. Green coverage graph greater change of Spathoglottis plicata three samples of beginning green covering is decline. However, for S6, only until its green coverage is 68 days does it see a rising gentle trend. For, S7 there is a slight increase from the first 33 days, and it continues until the end of the experiment observation (Fig. 16), the best medium is $\mathrm{S} 6\left(169.05 \mathrm{~cm}^{2}\right)$, followed by $\mathrm{S} 7$, with $\mathrm{S} 8\left(78.19 \mathrm{~cm}^{2}\right)$ as the worst.

\section{Conclusion}

We tested 8 plants and 3 medium and tested perlite base, thus achieving the results. The prescription for medium $\mathrm{pH}$ value is detected, with most of the medium showing a low-alkaline environment. The green coverage for media S6 (perlite to sandy loam is 8:2) is suitable for Alpinia speciosa the best growth $1040.5 \mathrm{~cm}^{2}$, followed is Duranta repens the growth $675 \mathrm{~cm}^{2}$, with Portulaca grandiflora as the third growth $365.12 \mathrm{~cm}^{2}$. The green coverage for media S7 (perlite to sandy loam is 5:5) is suitable for Alpinia speciosa the best growth $843.93 \mathrm{~cm}^{2}$, followed is Duranta repens the growth $587.38 \mathrm{~cm}^{2}$, with Zoysia matrella as the third growth $435.81 \mathrm{~cm}^{2}$. The green coverage for media S8 (perlite to sandy loam is 2:8) is suitable for Alpinia speciosa the best growth $501.03 \mathrm{~cm}^{2}$, followed is Duranta repens the growth $324.39 \mathrm{~cm}^{2}$, with Zoysia matrella as the third growth $298.55 \mathrm{~cm}^{2}$. Perlite to sandy loam medium is more suitable for Duranta repens, Alpinia speciosa, and Zoysia matrella with growth. S6 medium the best green coverage growth (biomass) $3185.49 \mathrm{~cm}^{2}$. Eight kinds of plants Alpinia speciosa the best green coverage growth (biomass) $2385.46 \mathrm{~cm}^{2}$. The prescriptions, whereby the ratio of lightweight medium (perlite to sandy loam) is $2: 8$, which is suitable for more kinds of plants. Different media prescriptions are well-grown planting combinations, in which one can choose different plant species based on the environment and in order to create biodiversity. This can be achieved to reduce the building load and may provide a good environment for the growth of plants and create space in favor of green roofs. 


\section{References}

[1] J. M. Bousselot, J. E. Klett, R. D. Koski, Moisture content of extensive green roof substrate and growth response of 15 temperate plant species during dry down, Hort Sci. 46(3) (2011) 518-522.

[2] C. C. Chen, L. S. Han, Research of residential area ecological green roof for reduce the heat efficiency in Taichung, Appl. Mech. Mater. 368-370 (2013) 1270-1273.

[3] C. C. Chen, Research of extensive green roof (Spring) for create comfortable environment in Taiwan City, Appl. Mech. Mater. 749 (2015) 420-424.

[4] C. C. Chen, C. L. Chen, Research of environmental friendly materials (recycling waste) is applied to green roof in planting and growth index difference, Adv. Edu. Sci. 10 (2015) 331-336.

[5] C. C. Chen, Research of green roof heat accumulating and cooling efficiency in urban, J. Archit. Plan. 16(2/3) (2015) 135-150.

[6] K. Durhman Angela, D. B. Rowe, L. Rugh Clayton. Effect of substrate depth on initial growth, coverage, and survival of 25 succulent green roof plant taxa. Hort Sci. 42(3) (2007) 588-595.

[7] R. Giridharan, S. S. Y. Lau, S. Ganesan, Nocturnal heat island effect in urban residential developments of Hong Kong, Energ. Build. 37 (2005) 964-971.

[8] Y. J. Lin, Study of sustainable type container extensive green roof, Chin Kung University, Doctoral Dissertation, Tainan. Taiwan (R.O.C.), (2012).

[9] S. Onmura, M. Matsumoto, S. Hokoi, Study on evaporative cooling effect of lawn gardens, Energ. Build. 33 (2001) 653-666.

[10] E. Palomo, D. Barrio, Analysis of the green roofs cooling potential in buildings. Energ. Build. (27) (1998) 179-193.

[11] T. Sendo, M. Kanechi, Y. Uno, I. Noboru, Evaluation of growth and green coverage of ten ornamental species for planting as urban rooftop greening, J. Japanese Soc. Horticult. Sci. 79(1) (2010) 69-76.

[12] T. Takakura, S. Kitade E. Goto, Cooling effect of greenery cover over a building, Energ. Build. 31 (2000) 1-6.

[13] N. H. Wong, Y. Chen, C. L. Ong, A. Sia, Investigation of thermal benefits of rooftop garden in the tropical environment, Build. Envir. 38 (2003) 261-270.

[14] E. S. Zhang, Y. H. Lai, B. C. Hou, Green roof media and plant relationship, saving energy and reducing carbon engineering methods--green roofs and green walls exchanges discussion and promotion exhibition, Taiwan (R.O.C.), (2009), pp. 17-24. 